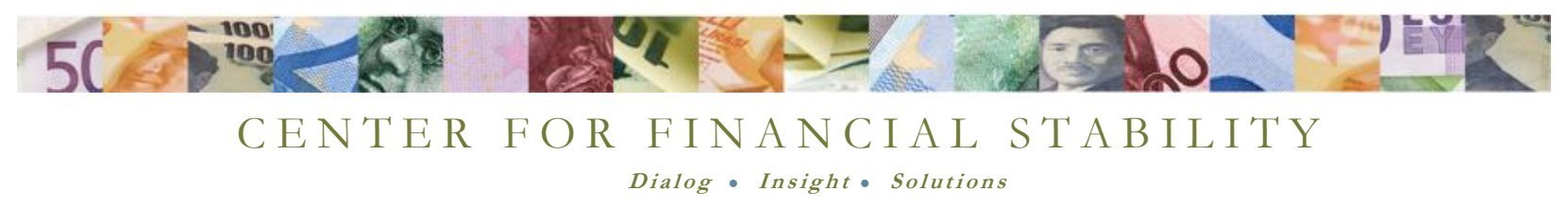

\title{
The New CFS Divisia Monetary Aggregates: Design, Construction, and Data Sources
}

\author{
William A. Barnett, University of Kansas, Lawrence, KS \\ Jia Liu, University of Kansas, Lawrence, KS \\ Ryan S. Mattson, University of Kansas, Lawrence, KS, \\ and \\ Jeff van den Noort, Center for Financial Stability, NY City
}

\section{Introduction}

The Center for Financial Stability (CFS) has initiated a new Divisia monetary aggregates database, maintained within the CFS program called Advances in Monetary and Financial Measurement (AMFM). The Director of the program is William A. Barnett, who is the originator of Divisia monetary aggregation and more broadly of the associated field of aggregation-theoretic monetary aggregation [Barnett (1980)]. The international section of the AMFM web site is a centralized source for Divisia monetary aggregates data and research for over 40 countries throughout the world. The components of the CFS Divisia monetary aggregates for the United States reflect closely those of the current and former simplesum monetary aggregates provided by the Federal Reserve. The first five levels, M1, M2, M2M, MZM, and ALL, are composed of currency, deposit accounts, and money market accounts. The liquid asset extensions to M3, M4-, and M4 resemble in spirit the now discontinued M3 and L aggregates, including repurchase agreements, large denomination time deposits, commercial paper, and Treasury bills. Table 1 documents the component clusterings within each aggregation level, and Figure 1 displays the resulting nesting of aggregates within aggregates, as the level of aggregation increases. When the Federal Reserve discontinued publishing $\mathrm{M} 3$ and L, the Fed stopped providing the consolidated, seasonally adjusted components. Also the Fed no longer provides the interest rates on the components. With so much of the needed component quantity and interest-rate data no longer available from the Federal Reserve, decisions about data sources needed in construction of the CFS aggregates have been far from easy and sometimes required regression interpolation. This paper documents the decisions of the CFS regarding United States data sources at the present time, with particular emphasis on Divisia M3 and M4.

The St. Louis Federal Reserve admirably initiated and maintains the five narrow Divisia monetary aggregates for the US and calls them MSI (monetary services indexes), in accordance with the theory and formulas derived by Barnett (1980). See Anderson and Jones (2011). But since the Federal Reserve no longer provides its former broad aggregates, M3 and L, the CFS is now maintaining the broad aggregates, Divisia M3 and Divisia M4, where M4 is similar to the Fed's former broadest aggregate, L. The CFS also is providing the narrow Divisia monetary aggregates, which are very similar to the St. Louis Fed's MSI aggregates. The primary distinction between the CFS's and St. Louis Fed's narrow Divisia aggregates is the measurement of the rate of return on capital (the benchmark rate), used within the Divisia formula. The CFS's and the St. Louis Fed's narrow Divisia quantity aggregates can be expected usually to behave similarly, although their dual user-cost price aggregates behave differently. The CFS is providing the narrow Divisia aggregates as a hedge against possible future freezes of the St. Louis Federal Reserve's MSI database. Such a freeze occurred for the five years of the financial crisis and Great Recession, (March 2006-April 2011). The properly weighted broad aggregates, such as Divisia M3 


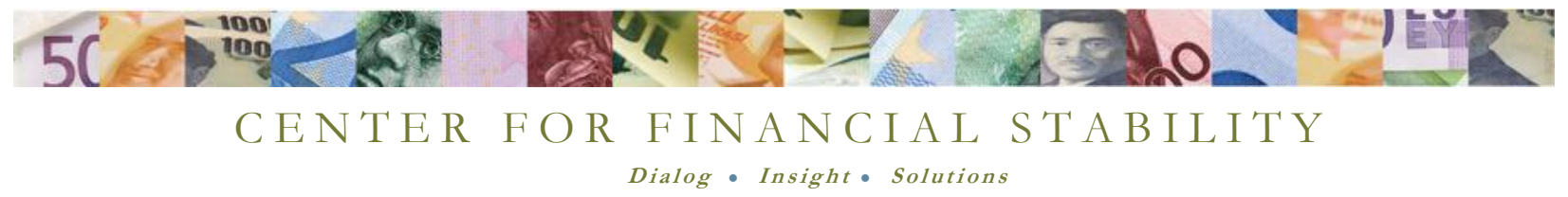

and Divisia M4, are for most purposes the most informative. See Barnett (1982). The AMFM site focuses primarily on the broad Divisia aggregates, which are provided solely by the CFS.

The Divisia aggregates in this CFS project are constructed for the purpose of making dependable statistics available as painlessly as possible to the public. The most recent data are updated monthly, will all details made public without subscription, at

http://www.centerforfinancialstability.org/amfm_data.php.

To that end and in accordance with the normal standards of science, we focus on the use of component data available to the public. To assure replicability, we are providing all component data and are withholding no sources or methodology or data from the public, as being proprietary to the CFS. That task has proved to be much more complicated than anticipated. For example, national average bank interest-rate data, previously collected and provided by the Federal Reserve, now are available only from a private source requiring subscription fees. While much of the needed data are available within the Federal Reserve by subscription to the private source, the Federal Reserve is currently not making that data easily available to the public ${ }^{1}$. Our task has been further complicated by the discontinuance of Federal Reserve collection of key components, such as repurchase agreements and bankers' acceptances, previously available from the St. Louis Federal Reserve Bank website. The resources we found for such hard-to find variables are provided in this paper, where available. Further complicating our work is the fact that, even when component quantities are available for the former $\mathrm{M} 3$ and $\mathrm{L}$ aggregates, those components often no longer are seasonally adjusted or consolidated. Without seasonal adjustment, monthly growth rates contain seasonal noise; and without consolidation, simplesum accounting aggregation is vulnerable to distortions not consistent with reputable accounting practices.

\section{Data Sources}

Constructing the Divisia monetary aggregates requires not only the quantities of monetary components but also their interest rates. Following discontinuation of Federal Reserve collection of some interest-rate and deposit-quantity data, we have had to find other public and private sources of those data. ${ }^{2}$ While the Federal Reserve has agreements with the firms that now collect much of the relevant data, the Fed does not presently provide them in their Statistical Surveys or through the St. Louis Federal Reserve Bank's online archive tool, FRED (Federal Reserve Economic Data). Table 2 documents our current components quantity and interest-rate data sources. The following paragraphs also document prior sources used in producing the historical series, when sources were changing.

Much quantity (volume) data are available from the FRED website. From FRED we can find many of the aggregates' component levels, with the exception of large-denomination time deposits, short-term treasury bills (T-bills), and overnight repurchase agreements (repos). Large time deposits can be found in the Federal-Reserve-Board's H.8 release, "Survey of Assets and Liabilities at Commercial Banks." ${ }^{3}$ While large time deposits were once readily available on FRED, current data from the H.8 are no longer available there directly; one must access the data download program on the Federal-Reserve-

\footnotetext{
${ }^{1}$ The authors would like to thank Richard G. Anderson at the St. Louis Federal Reserve Bank for providing much of the needed data. The authors would also like to thank Steve Hanke, David Beckworth, and Peter Ireland for their valuable input and suggestions.

${ }^{2}$ See The Federal Reserve Discontinuation Memo on M3 and its Components.

${ }^{3}$ http://www.federalreserve.gov/releases/h8/current/default.htm. See page 3, line 32 of the H.8 Survey for the seasonally adjusted levels of large time deposits.
} 


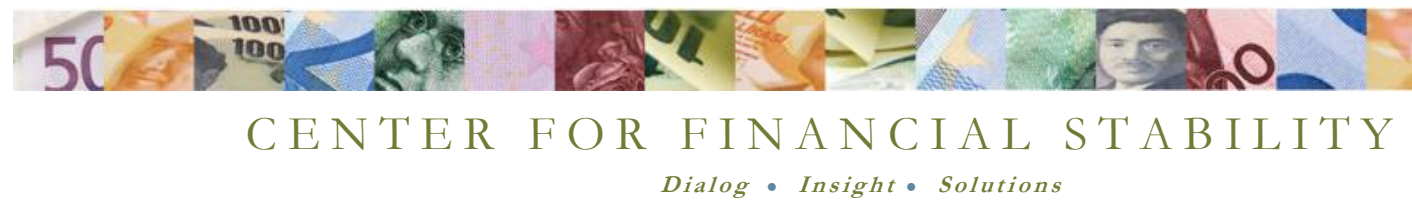

Board's "Statistics and Historical Data" website. T-bills are available from the "Monthly Public Statement of Debt" on the United States Treasury website ${ }^{4}$. Repos are available through the New York Federal Reserve Bank's "Primary Dealer Statistics" survey ${ }^{5}$; however, data before the beginning of this survey had to be estimated using the now discontinued overnight and term RP level, provided by FRED for commercial banks. Commercial paper levels are available on FRED only back to 2001; however, the pre-2001 data can be found in the commercial paper section of the Federal Reserve Board Statistics site ${ }^{6}$ for monthly data and table L.208 of the Z.1 release, "Flow of Funds Survey," provided by the Federal Reserve Board. ${ }^{7}$ Quantity levels for the limited duration of "super negotiable orders of withdrawal" (super NOWs) and money-market deposit accounts (MMDA) were provided in the data set used by Anderson and Jones (2011), and in previous issues of the Federal Reserve Bulletin.

Interest-rate data are more difficult to collect, as the Federal Reserve does not make them easily available to the public or to researchers not on their staff. The Federal Reserve itself no longer tracks the national averages of interest rates for bank products, nor does the St. Louis Fed currently provide them on FRED. Federal Reserve Board staff are provided these data from outside sources, with whom the Fed has contracts: (1) Bankrate.com, a company that keeps track of interest rates on deposit accounts, mortgage loans, and credit-card rates; (2) ICAP, a London based firm, which provides interestrate data for overnight and term repurchase agreements; and (3) iMoney.net, which tracks interest rates for money-market mutual funds.

Interest rates on checking, savings, money market-accounts, and certificates of deposit of various maturities and levels (regular or "jumbo") are collected and provided by Bankrate.com through two surveys: the weekly interest-rate roundup and the overnight daily internet survey. The weekly "Bank Rate Monitor" survey is collected from the ten largest banks (five commercial and five thrift institutions) in the 25 largest metropolitan areas of the United States. The result is a weekly sample of 250 of the largest banks by assets in the United States. The Bank Rate Monitor Survey is available for a paid weekly subscription, which the Fed acquires and provides to its in-house researchers. The public are not currently able to download the raw data to replicate the Fed's research without a subscription. The second survey is a daily "Overnight Average," provided freely on Bankrate.com's website, or available using Bloomberg for commercial banks and credit unions. The Overnight Average Survey is conducted by collecting the interest rates offered for interest-checking accounts, MMDAs, jumbo CDs of various terms, and mortgage and credit-card offer-rates available and advertised online. The overnight CD data follow the Bank Rate Monitor rates fairly closely; however the MMDA and interest checking rates for commercial banks are significantly higher and more volatile (as Bankrate.com warns on its website explanation). The discrepancy is accounted for in the survey method: Bank Rate Monitor

\footnotetext{
${ }^{4} \mathrm{http}: / /$ www.treasurydirect.gov/govt/reports/pd/mspd/mspd.htm. There is no easily downloadable time series data for the level of Treasury bills from the MSPD. The authors can provide that series on request to simplify other efforts to replicate the data.

${ }^{5}$ http://www.newyorkfed.org/xml/gsds_finance.html, under the tab "Financing."

${ }^{6}$ http: www.federalreserve.gov/releases/cp/volumnestats.htm. See the Data Download Program for historical survey data.

${ }^{7} \mathrm{http}: / /$ www.federalreserve.gov/releases/z1/Current/. The data are taken on a quarterly basis in the Z.1 survey.
} 


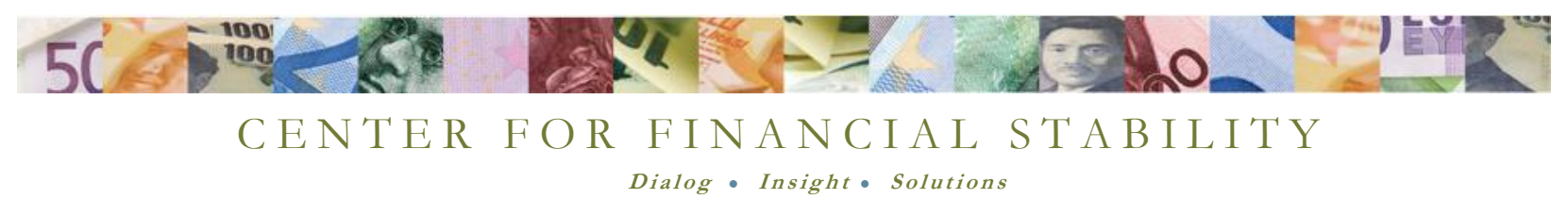

surveys the same ten largest banks each week in 25 cities, while the overnight average survey compiles rates offered from various banks online. The overnight survey often collects only 30 to 40 daily-rate offers from different banks. These online bank offers are generally higher than the average offers to attract customers.

As of the writing of this paper, the Federal Reserve Bank of St. Louis has agreed to begin posting the Bankrate.com data on the FRED website in spring of 2012. The St. Louis Fed has permission from Bank Rate Monitor to make the average interest-rate data on various account types public, and we are indebted to Richard Anderson at the St. Louis Fed for providing those interest-rate data to us in advance of the anticipated public availability on FRED.

Money-market funds are collected by iMoneyNet. Federal Reserve researchers have access to the data, which again are not currently provided by the Federal Reserve Board or FRED to the public. A subscription is needed to acquire the data from iMoneyNet. We are indebted to Richard Anderson for providing those data to us. But the public can acquire an alternative source available for free. The "7Day Average Rate" on money-market funds is available to the public on Bankrate.com through their trend graph tool (which cites the source as iMoneyNet). There is no distinction there between retail or institutional money-market funds, so one rate is used for both, when a separate institutional rate is not available to the public. The separate retail and institutional money-market fund rates provided to us by the St. Louis Fed were used until October of 2011. Starting in November of 2011, the alternative 7-Day Average Rate available on Bankrate.com is used for both retail and institutional interest rates to permit replication with data available to the public.

Repo rate data before 1997 had to be estimated by regression on T-Bill rates. After 1997 the interest rate data came from the London firm ICAP, which takes an average of repo rates twice daily for their I-Repo index, found on Bloomberg and in the Wall Street Journal.

\section{Divisia M1 Aggregate}

The Divisia M1 aggregate contains the most liquid monetary-asset components. Seasonally adjusted levels of currency, travelers' checks, and non-interest-bearing deposits are added and then paired with a zero interest rate. Currency is the measure of cash available within the US economy outside of the Federal Reserve. Currency quantities are available in the Fed's H.6 Survey and on FRED. Travelers' checks are freely available on FRED, as well. Like currency, traveler's checks are assumed to have a zero own rate or return.

While demand deposits can earn an implicit rate of return, we do not impute an implicit rate of return to demand deposits. Anderson and Jones (2011) and Anderson, Jones, and Nesmith (1997) investigated the possibility of assigning a non-zero own rate to demand deposits and proposed alternative methods, originally suggested by Barnett and Spindt (1982), Farr and Johnson (1985), and Thornton and Yue (1992). In these imputation procedures, household and business demand-deposits are separated. As the relevant separated data are not readily available, the own rate of return for demand deposits in the St. Louis Fed's Divisia monetary aggregates is set to zero. The St. Louis Fed calls 


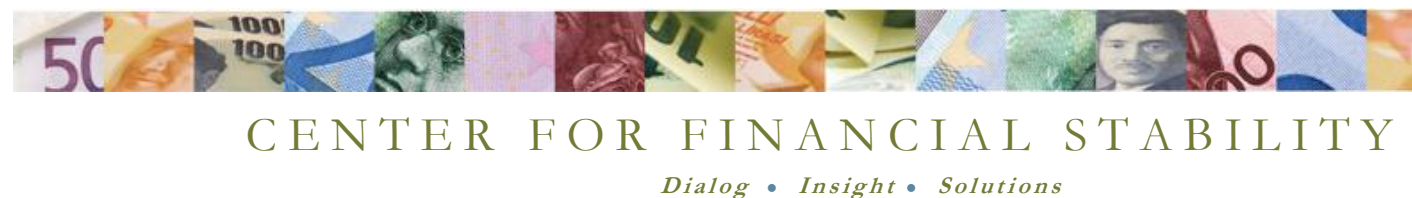

its Divisia monetary aggregates "monetary services indexes" (MSI). While acknowledging that banks can and do offer an implicit rate of return, especially to large depositors, we follow the same procedure as the St. Louis Fed in foregoing the imputation of an implicit rate of return to demand deposits. The reason is the lack of easily and openly-accessible data for such an imputation.

The levels of interest-bearing checking accounts (labeled as "other checkable deposits" or OCDs) are also included in the aggregate. The interest rates on those accounts are available from either the Bank Rate Monitor Survey or the Overnight Survey provided by Bankrate.com. Acquiring the own rate of return for other checkable deposits before 1987 (the beginning of the Bank Rate Monitor survey) is complex. From 1967 to 1973, OCDs are assumed to have a zero checking account yield, because of the lack of data. From the period of 1974 to 1980, the own rates were the maximum allowed, which was $5 \%$. The St. Louis Fed's MSI index sets the own rate to be the minimum of either the $5 \%$ regulated limit or the average of the most common interest rates reported on savings deposits in archived issues of the Federal Reserve Bulletin. We simplify this period by adopting the 5\% regulated limit for 1974 to 1980 , and the $5.25 \%$ maximum for the period from 1982 to 1983 . Thrift-institution interest-checking accounts are assumed to yield the same legal limits. In 1983, super NOW accounts were introduced, and the super NOW interest rates are used for both other-checkable-deposits (OCDs) and the super NOW accounts. The super NOW rates are available from the Federal Reserve Board in the Special Supplementary Table of the Federal Reserve Bulletin back issues, accessible in the Federal Reserve Archival System for Economic Research (FRASER) between 1983 and 1985. After January 1986, OCDs include super NOW accounts. For the year of 1986, we use the average rate paid on NOW accounts as provided by the Federal Reserve Board. We acquired that interest rate from the MSI component spreadsheet provided to us by Richard Anderson for the paper Anderson and Jones (2011). After 1987 the rate or return on interest-bearing checking accounts is from the Bank Rate Monitor Survey.

Demand deposits and other-checkable-deposits (OCDs) are adjusted for retail sweeps. This important adjustment procedure is described in the section below on "Sweeps". Like the simple-sum and MSI aggregates, the Divisia M1 monetary aggregate would be underestimated, if unadjusted postsweeps data were used for demand deposits and OCDs.

As is clear from the procedures described above, a clear and consistent data set on bankaccount interest rates is needed and would be useful, not only for construction of Divisia monetary aggregates, which are far superior to the official simple-sum aggregates, but also for other research on banking, finance, and monetary economics. We look forward to the anticipated FRED data availability, planned to begin in the spring of 2012.

\section{Divisia M2 Aggregate}

The Divisia M2 aggregates include those components in the Divisia M1 aggregate, as well as savings deposits, money-market deposit accounts, small-denomination time deposits, and retail money funds. All of these component quantity levels come from the St. Louis Federal Reserve's FRED database, and the interest rates come from BankRate.com, with the exception of the national average of interest rates for retail and institutional money market funds. The BankRate.com data are provided to us by 


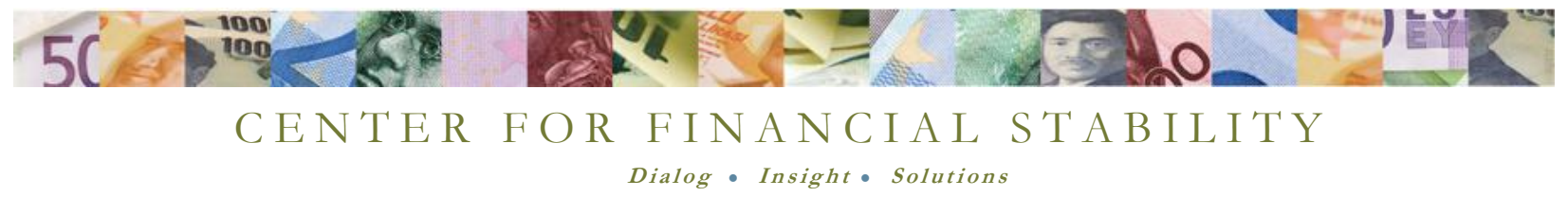

Richard Anderson at the St. Louis Federal Reserve under an agreement with BankRate.com to make the component data public.

Levels of money-market deposit accounts (MMDA) on FRED come from the Federal Reserve Board's H.6 survey. Prior to 1991, MMDA and savings deposit quantities were treated as different levels. MMDA level data began in 1982 and continue as separate levels until 1991. Savings deposits without inclusion of MMDAs go back to 1967 and continue to 1991 as well. Since 1991, MMDA and savings-deposits data have been merged and are counted as one item.

Interest rates from MMDA and savings accounts were treated separately up to October 1991. Following Anderson, Jones, and Nesmith (1997), we used the maximum legally-available rate until 1983 for savings and MMDA accounts, with thrift institutions' maximum rate being the commercial-bank rate increased by 25 to 75 basis points, depending on the time period. From 1983 to 1991, MMDA levels are paired with average interest rates reported by the Federal Reserve Board in the data set provided by the St. Louis Fed for the paper, Anderson and Jones (2011). From 1986 to 1991, that data set is also used to acquire the average monthly interest-rate paid on savings deposits. After 1987, MMDA and savings levels are combined and coupled with the interest rates on MMDAs, provided by Richard Anderson at the St. Louis Fed from the weekly Bank Rate Monitor survey.

Small denomination time deposit levels are also readily available on FRED from the H.6 survey of the Federal Reserve Board. Seasonally adjusted levels are consistently taken and posted from 1967 to the current period. These deposit denominations are less than $\$ 100,000$, unlike their large denomination or "jumbo" counterparts measured in the Board's H.8 Survey.

Small denomination time deposits require a similar mix of data series. From 1967 to September 1983, the 6-Month CD interest rate for commercial banks is used as the own rate for small time deposits. The thrift rate is computed by adding 25 basis points to the commercial bank interest rate. Between October 1983 and August 1991, the own rate is computed to be the average rate of return paid by commercial banks and thrift institutions for balances of less than $\$ 100,000$ with maturities of 92 to 182 days. After August 1991, the 6-Month CD rate for commercial bank and thrift institutions is used from the Bank Rate Monitor survey, as provided by the St. Louis Federal Reserve Bank (Richard Anderson).

The Federal Reserve still posts money-market funds on FRED, as they contribute heavily to the simple-sum measures of M2 and MZM. The seasonally adjusted levels posted on FRED come from the Board's H.6 Money Stock Measures survey, and stretch back consistently to our 1967 starting point for both retail and institutional money-market funds. Retail money-market funds are those offered primarily to individual investors and have a low minimum investment quantity. Institutional money funds are designed with businesses in mind, and have high investment requirements, but also provide higher interest-rate return than retail money-market funds. For some businesses, the institutional money-market funds are linked to a company's demand deposits or other-checkable-deposit (OCD) accounts, with funds being "swept" into money-market funds at the end of the business day, when demand deposit and OCD accounts are not in use. This "Commercial Sweeping" is covered in more 


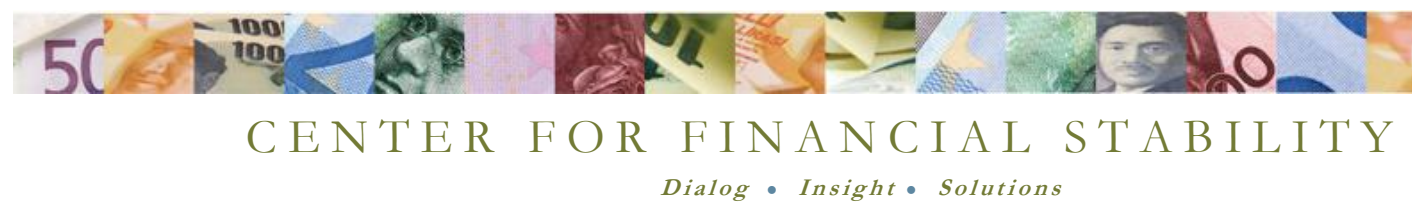

detail in the "Sweeps" section below. It should be noted that any M2 aggregates, Divisia or simple-sum, will be underreported, unless they include the institutional money-market funds that include these sweeps.

From 1974 to 1987, there is only one rate to match with both retail and institutional moneymarket funds. These data are provided by the St. Louis Fed in Anderson and Jones's (2011) MSI component data, and are cited in that paper as unpublished data obtained from the Federal Reserve. The separate retail and institutional money-market fund interest rate data from 1987 to 2011 also come from Anderson and Jones (2011), which cites the source as an unpublished Federal Reserve data set from iMoney.net. The money-market fund rates have not yet been posted on FRED, and are otherwise only available through a subscription to iMoney.net. We are indebted to Richard Anderson for providing those data to us. From November 2011 to the present we use the 7-Day Average Money Market Fund Rate available on Bankrate.com for both retail and institutional money-market funds. The Bankrate.com source is easily accessible and available to anyone with an internet browser using the graphing tool.

Each Divisia M2-variant aggregate includes or excludes certain components, in parallel with the corresponding simple-sum aggregates commonly used by the Fed. Divisia M2M incorporates savings deposits, MMDA, and retail money-market funds, but not small time deposits (small-denomination CDs). Divisia MZM includes the components of Divisia M2M, along with institutional money-market funds. Divisia M2 omits institutional money-market funds, but incorporates small-denomination time-deposit levels and rates. Divisia M2-ALL reincorporates institutional money-market-fund data into the components of Divisia M2.

The Divisia M2 aggregates are designed to follow closely the structure of simple-sum and MSI variants of M2. Further empirical testing on how to cluster the Divisia M2 aggregates' components would be useful, but is left to future research.

\section{Divisia M3, M4-, and M4 Aggregates}

The Divisia M4 aggregates (Divisia M4- and Divisia M4) are derived by incorporating into Divisia $\mathrm{M} 2$ the levels and rates of return on the primary, negotiable, money-market securities, including commercial paper, large-denomination time deposits, overnight repurchase agreements (repos), and short term treasury bills (T-bills). Being highly liquid, these primary securities contribute to the economy's flow of monetary services, but not to the same degree as currency and checkable deposits. These aggregates are meant to substitute for the now discontinued Federal-Reserve simple-sum $\mathrm{L}$ aggregate, but with proper aggregation-theoretic weighting of the components, as opposed to the former simple-sum aggregation, which produced a greatly distorted measure of the economy's liquidity, by weighting all components the same as legal means of payment. Divisia M4- removes T-bills from Divisia M4, for use in applications requiring separation of monetary from fiscal policy effects. Divisia M4 includes T-bill rates, to round out the most general Divisia aggregate within this project. Acquiring the necessary data to compute M4 was challenging, since many of the components of $L$ are no longer provided by the Federal Reserve Board, especially in seasonally-adjusted consolidated form. 


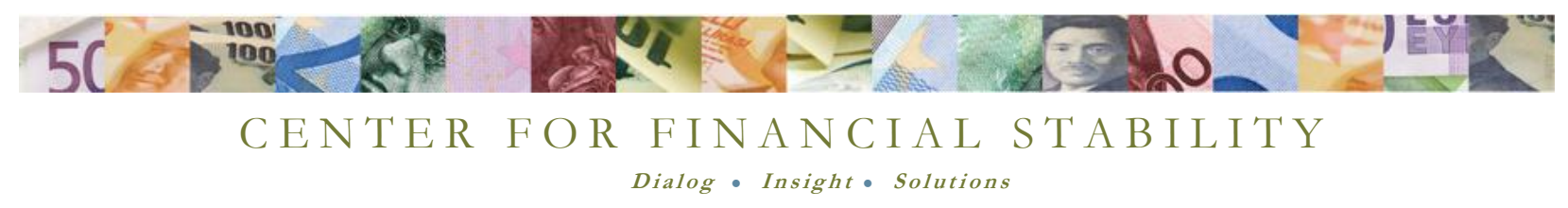

The interest rates for commercial paper are available on FRED and also on the Board's H.15 Survey of Selected Interest Rates. From 1967 to 1996, the interest rate we use on commercial paper is the interest rate on "Finance Paper Placed Directly" with a three month maturity. We use that rate, since it is the only three-month-maturity rate available for "Financial or Nonfinancial Commercial Paper" during that time period, and for overlapping periods tracks the AA financial paper rate well. The rate for finance paper is available through the Federal Reserve Board Statistics H.15 Selected Interest Rates survey, using the data download program ${ }^{8}$. From 1997 to the present, the "AA Three Month Financial Commercial Paper" rate is used as the own rate of interest and is available on FRED. The rate of return on financial commercial paper is used, since commercial paper issued by financial companies is the bulk of commercial paper issued. Commercial paper with 3-month maturity was the focus, since 3-months is the middle term of the maturities tracked by the Fed. The Fed provides data on maturities between one and six months.

Commercial paper quantity data are readily accessible on the Federal Reserve Board website and on FRED. Quarterly data from the Z.1 Flow of Funds Survey had to be used before 1991 as monthly asset level data on commercial paper was unavailable. These figures are available in L.208 Table. After 1991, asset levels can be found in two available surveys on the commercial paper site of the Board of Governors. The first survey is the "old structure" survey, starting in January of 1991 and including monthly levels. In 2006, several changes were incorporated into the commercial paper calculations ${ }^{9}$, and the Federal Reserve Board had to begin a different "new structure" series that continues today. The new series data begin in January 2001 and continue to the present. To link these series, a regression was run on the overlapping periods (January 2001 to March 2006) of the old and new survey, and past values of the "new structure" were estimated from the "old structure."

The own rate of return on large-denomination time deposits is the 6-Month Secondary Certificate of Deposit Rate available on FRED. This follows from the method of Anderson and Jones (2011) in calculating the MSI for M3 components before their discontinuance. Fortunately the interest rates for CDs are still easily available on FRED. On the other hand, levels for large-denomination time deposits were discontinued in FRED and are accessible in the Federal Reserve Board's H.8 "Survey of Assets and Liabilities of Commercial Banks."

The levels of non-seasonally adjusted T-bills were compiled into a data sheet from the "Monthly Public Statement of Debt," provided by the United States Treasury Department. The levels include those T-bills held by the public plus the amount held by intergovernmental agencies. There are no large time-series data available for download for levels of T-bills, but the compilation of data we used is available upon request. ${ }^{10}$ The own rate of return for T-bills is the secondary-market rate for the 3month maturity T-bill, available on FRED back to 1967. These rates originally come from the Board's H.15 "Survey of Selected Interest Rates" and can be accessed on the Federal Reserve Board website as well.

\footnotetext{
${ }^{8}$ http://www.federalreserve.gov/datadownload/Build.aspx?rel=H15.

${ }^{9}$ A description of these changes can be found here: http://www.federalreserve.gov/releases/cp/about.htm.

${ }^{10}$ Otherwise a potential replicator will have to wade through monthly scanned documents back to 1967.
} 


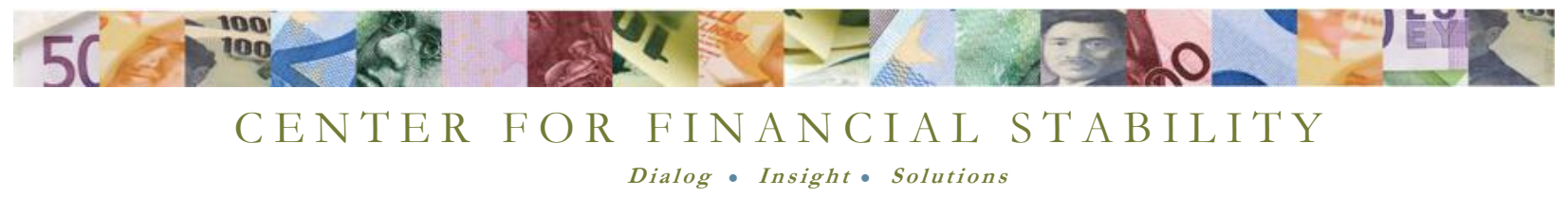

Levels of overnight and term repos are available through the New York Federal Reserve Bank's Primary Dealer Statistics on the New York Fed's website. However those data only stretch back to November of 2001. FRED contains levels of overnight and term repos that were used in the now discontinued M3 aggregate; however, those data only extend from 1970 to 2006. The two data series are also not equal. The New York Fed repos are those processed daily between the "primary dealers" (banks, security dealers) and the Fed, and are very large. The repos used in the former official M3 aggregate, available on FRED, were those issued by commercial and thrift banks to customers. Those quantities are relatively low. We chose to estimate the 1970 to 2001 values of the New York repos using the estimated coefficient of a regression of the New York Fed values on the FRED values for the overlapping time period of 2001 to 2006. After 2001, the actual values from the New York Fed overnight and term repos are used, up to the most current period.

The rate data are provided by the London-based money broker, ICAP. ICAP's I-Repo index is an average of interest rates on repurchase agreements taken once at 12:00 PM EST ("AM Rate") and 6:00 PM EST ("PM Rate"). For repo levels from 1997 to the present, a time series of repo rates was provided by Datastream Navigator, and correspond to the PM rate taken. These values are available using the Bloomberg ${ }^{11}$ website, and searching for the "I-Repo Index". The I-Repo Index uses the morning value of repo interest rates and corresponds to the AM rate. The AM I-Repo rate can also be found in the Wall Street Journal ${ }^{12}$. Repo rate data before 1997 are unavailable, so the repo rates were estimated in overlapping time periods of the Datastream series by regression on T-Bill rates (from FRED), which were found to be closer than other interest rates to the repo rates. Using the estimated regression coefficient, the repo rates were estimated back to 1970, using the available T-bill rates.

The Divisia M3 aggregate contains a similar set of components to the discontinued simple-sum aggregate, produced by the Federal Reserve before 2006. Along with the components of M2-ALL ${ }^{13}$, Divisia M3 includes large time deposits and overnight and term repurchase agreements.

The Divisia M4 aggregates are the broadest available monetary aggregates and are supplied only by the CFS in its AMFM program. They reflect the spirit of the monetary aggregate, $L$, formerly available from the Federal Reserve, and the Divisia M4 aggregates capture most of L's former components. A noted absence is bankers' acceptances. The interest rates for bankers' acceptances, according to the Board's H.15 "Survey Historical Data," were available through the firm, Telerate, which provided the Fed with those rates until June, 2000. A search for the company shows it was bought by Thomson-Reuters. Telerate became "Moneyline Telerate, Inc." in 2001, and does not seem to provide the bankers' acceptance rates anywhere. When searching for bankers' acceptance levels, we learned, from the description of the L.208 Open Market Paper table of the Z.1 Survey, that Bankers' Acceptance levels are no longer differentiated from commercial paper. Any levels of bankers' acceptances are included in the

\footnotetext{
${ }^{11}$ http://www.bloomberg.com/apps/quote?ticker=IREPUSOA:IND

12 http://online.wsj.com/mdc/public/page/2_3020-moneyrate.html

${ }^{13}$ Institutional money-market funds used to be a part of simple-sum M3, and are not included in the "old" M2 definition. Currently they are used in MZM and M2-ALL.
} 


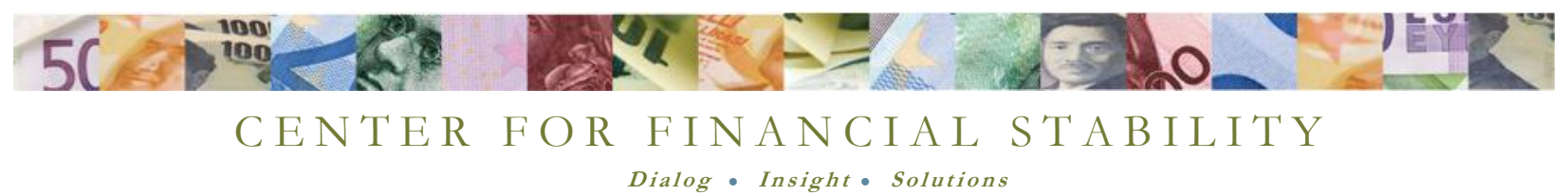

commercial paper levels, and coupled with a commercial paper rate, since the two are no longer separated. ${ }^{14}$

\section{Sweeps}

It is well known that retail sweeps programs have a decreasing effect on the quantities of components in M1 (both simple-sum and Divisia). Retail sweeps occur when banks move money on their accounting books from non-interest bearing or low-interest-bearing checking accounts (demand deposits or OCDs) to savings and MMDA accounts, which are not subject to reserve requirements. Such swept funds are not included within official M1. Without an adjustment for the funds being "swept" from Divisia M1 components to Divisia M2 components, Divisia M1 will be biased downwards. It should be observed that such sweeps are serviced as checking accounts, so the "sweeps" are little more than an accounting measure, unrelated to the economics of the swept funds' services, which belong in M1. For narrow monetary aggregates, a corrective sweep adjustment is necessary to avoid economic distortion of the services being measured.

To account for bookkeeping sweeps from demand deposit and OCD accounts into savings and MMDA deposit accounts, the total amount of estimated sweeps is taken from the St. Louis Federal Reserve website, under the category of "cumulative sum of newly initiated retail sweeps"15. The sweeps levels are allocated to demand deposits and OCDs, based on the shares of total demand deposits and OCDs in commercial and thrift accounts. The amounts added to demand deposits and OCDs are then subtracted from the savings deposits, based on the total shares of savings deposits in commercial and thrift institutions.

The sweeps data on the St. Louis Federal Reserve Bank website measure the amount of new sweeps programs initiated in MMDA accounts. These new programs are then summed over time to get the cumulative amount of sweeps. This cumulative figure is the amount used in our adjustment procedure, since that figure is a simple, available measure of total sweeps in the system. But this figure underreports the amount of sweeps, since banks have no obligation to report the level of sweeps they initiate.

To maintain a current monthly release, the previous month's sweeps values are used. For example, the January 2011 sweeps level is used for the February 2011 Divisia calculation. The lag value is chosen as the proxy (martingale forecast) for the current month's sweeps, since the sweeps levels are not available to the public until nearly two months after the corresponding month. While the value is available internally to Federal Reserve Board researchers in the proper month, contemporaneous sweeps data are not posted on the St. Louis Fed's website until the following month. To assure replicability by the public, we are avoiding use of internal Federal Reserve data prior to availability to the public. We recalculate the prior month's Divisia indexes, as soon that month's sweeps become available to the public. As a result, only the current months aggregates depend upon lagged sweeps. In an

\footnotetext{
${ }^{14}$ http://www.federalreserve.gov/apps/fof/DisplayTable.aspx?t=I.208. See “description" for note on bankers' acceptances.

${ }^{15}$ http://research.stlouisfed.org/aggreg/swdata.html.
} 


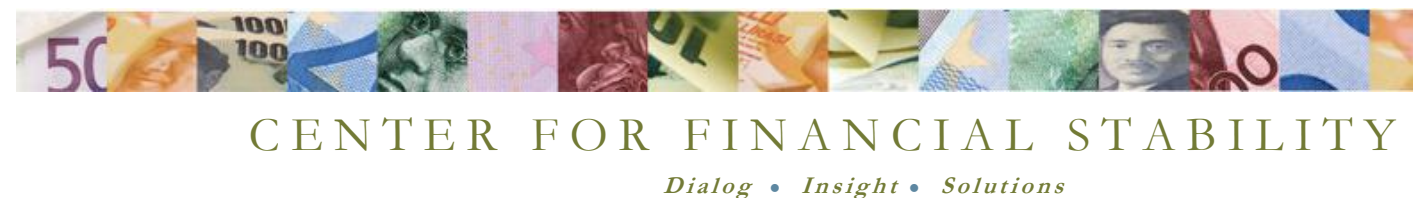

experiment, the Divisia indexes were calculated using both the current month (for those months available) and the lagged month, and we found no significant differences between the two series. As a result, the recursive recalculations of the prior month's aggregates produce negligible changes to the historical data.

Let DD be demand deposits, DDS be sweeps-adjusted demand deposits, OCDC be other checkable deposits at commercial banks (interest bearing checking accounts), OCDCS be the sweepadjusted OCDC, OCDT be other checkable deposits at thrift institutions, OCDTS be the sweeps-adjusted $O C D T$, and $C D$ be the level of cumulative sweeps provided by FRED. Then the adjusted levels are as follows.

$$
\begin{gathered}
\mathrm{DDS}=\mathrm{DD}+\mathrm{CS} * \frac{\mathrm{DD}}{(\mathrm{DD}+\text { OCDC }+ \text { OCDT })} \\
\text { OCDCS }=\text { OCDC }+\mathrm{CS} * \frac{\mathrm{OCDC}}{(\mathrm{DD}+\text { OCDC }+ \text { OCDT })} \\
\text { OCDTS }=\text { OCDT }+\mathrm{CS} * \frac{\text { OCDT }}{(\mathrm{DD}+\text { OCDC }+ \text { OCDT })}
\end{gathered}
$$

Similarly, the process adjusting savings deposits for sweeps is as follows, where SAVC are savings deposits at commercial banks, SAVCS are the sweeps adjusted-level of SAVC, SAVT are savings at thrift institutions, and SAVTS are the sweeps-adjusted level of SAVT:

$$
\begin{aligned}
& \text { SAVCS }=\text { SAVC }-\mathrm{CS} * \frac{\mathrm{SAVC}}{(\mathrm{SAVC}+\mathrm{SAVT})} \\
& \mathrm{SAVTS}=\mathrm{SAVT}-\mathrm{CS} * \frac{\mathrm{SAVT}}{(\mathrm{SAVC}+\mathrm{SAVT})}
\end{aligned}
$$

Furthermore, commercial sweeps programs produce further understatement of narrow monetary aggregates. Jones, Dutowsky, and Elger (2005) have noted a significant increase in demanddeposit amounts "swept" into institutional money-market funds and other financial instruments, since the 1990s. Unlike retail sweeps, customers tend to be informed of these commercial sweeps, when banks move funds from accessible demand deposits to a linked investment account. Since commercial sweeps are more than just accounting devices, customers share in the earnings from those sweeps. Jones et al. (2005) provide a method for adjusting the narrow monetary aggregates to account for commercial sweeps by moving amounts out of institutional money-market funds and back into demand deposits and other checkable deposits. However, this adjustment would not account for those commercial sweeps in unlinked investment accounts. There are no data for those sweeps or for those linked to financial instruments other than money-market funds. The problem is minimized by broad monetary aggregates, such as the Divisia M4 aggregates. Because of lack of data, we have not compensated our narrow Divisia monetary aggregates for commercial sweeps, and we do recommend the use of broad aggregates to offset the problem. But even without this problem, there are many good 


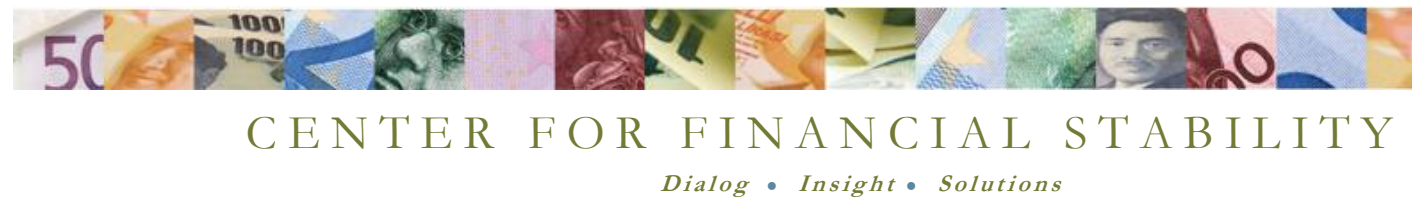

reasons to prefer a properly weighted broad aggregate to a narrow aggregate, which arbitrarily assigns a weight of zero to some liquid assets, providing monetary services to the economy.

\section{The Benchmark Rate}

The user-cost price of the services of a monetary asset depends upon the interest foregone to consumer the services of the asset. The interest foregone depends upon the interest paid by the asset and the higher expected rate of return on the benchmark rate, defined to be the rate of return on pure investment capital, providing no monetary services. To determine the benchmark rate, which cannot be less than the own yield on a monetary asset providing monetary services, we compute the upper envelope over the own rates of return on the components of our broadest monetary aggregate, M4. We do not constrain the upper envelope to the components of the St. Louis Federal Reserve's narrower M2-ALL aggregate. The benchmark rate can never be less than the upper envelope level at any period of time. But the benchmark rate normally should exceed that upper envelope, since the benchmark rate is a proxy for a shadow rate having no liquidity, being the theoretical rate of return on pure capital producing no services other than investment yield. In addition, such pure capital investment return is normally taxed at a lower rate than the rate of interest on monetary asset accounts. For those reasons, we include within the computation of our upper-envelope the "Weighted Average Effective Loan Rate, Low Risk, 31 to 365 Days, All Commercial Banks" (C\&I Loan Rate) from FRED. We are indebted to Akiva Offenbacher at the Bank of Israel for this suggestion, which also is used in computation of the Bank of Israel's new Divisia monetary aggregates.

The low-risk bank-loan rate was chosen to keep within a "risk neutral" setting required by the derivation of the Divisia monetary aggregate formula we are using. See Barnett (1980). While we have available the risk-adjusted formula to account for risk aversion, we are not currently using that extension. The C\&I loan rates come from the E.2 "Survey of Terms of Business Lending," provided by the Federal Reserve Board. The secondary negotiable CD loan rate and the Eurodollar deposit rate were considered for comparison. The three month secondary negotiable $C D$ rate and the six month Eurodollar deposit rate is available on FRED and in the Board's, H.15 "Survey of Selected Interest Rates." But we decided upon the C\&l loan rate, which acts as an upper limit to the interest rate a bank will offer on any deposit category. A bank will not pay out to its depositors more than it earns in interest on the short-term loans it makes. The low-risk C\&I loan rate is most often the maximum of the interest rates in the upper envelope, as expected. The C\&I loan rates are available only as quarterly data. As a result, that rate in our benchmark-rate computation is used for all three months in the quarter. The Bank of Israel has that rate monthly.

Since the C\&I loan rates is not available before 1997, just the upper envelope of the M4 component interest rates The lack of C\&l loan rates leads in some periods to commercial financial paper having a zero user-cost level, since its rate is the highest for those periods. For the benchmark rate, before 1997, 100 basis points are added to keep user costs from becoming zero, following a methodology by Anderson and Jones (2011). Once C\&I loan rates are introduced, the addition of 100 basis points is no longer necessary, as $C \& I$ loan rates are always greater than those rates banks offer to pay on the component aggregates. 


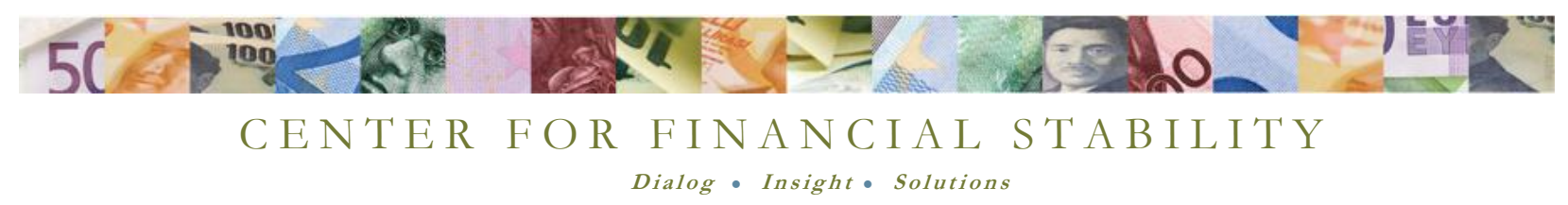

\section{Seasonal Adjustment and Consolidation}

Some components of M3, M4-, and M4 are no longer available in seasonally adjusted or consolidated form. Specifically the levels of short term treasury bills and overnight repurchase agreements are not seasonally adjusted by their respective sources. We employed the commonly used $\mathrm{X}-12$ ARIMA (autoregressive integrated moving average) procedure to seasonally adjust the data, as is done by the United States Census Bureau ${ }^{16}$.

A detailed description of the methods and theory of X-12 ARIMA can be found at the US Census Bureau website ${ }^{17}$, and its advantages are outlined in a study by Thorp (2004), defending the Bank of England's switch to using the X-12 ARIMA seasonal adjustment for its monetary components. A further study of X-12 ARIMA by the European Central Bank (2000) details its use in measuring the money supply of the European Union in the exhaustive Seasonal Adjustment of Monetary Aggregates and HICP for the Euro Area. Our analysis of the data after seasonally adjusting T-bills and Repos produced no reason to use an alternative method to the mainstream.

The unadjusted levels are readily available in the sources described in this paper. To access nonseasonally adjusted levels of T-bills and repurchase agreements, one need only visit the Monthly Statement of Public Debt on the US Treasury website, and the New York Federal Reserve Bank's Primary Dealer Survey. With those unadjusted resources, any seasonal adjustment method could be applied. Alternatively, to avoid seasonality distortions in non-seasonally adjusted broad aggregates, one could calculate only year-over-year growth rates ${ }^{18}$. All components used in the narrower Divisia aggregates (M1 and the M2 family) are seasonally adjusted. However, to properly measure the broader aggregates that include t-bills and repos, either seasonal adjustment must be performed or alternatively only yearover-year growth rates should be used to avoid seasonality problems.

On the CFS's Advances in Monetary and Financial Measurement website, we display the seasonally adjusted year-over-year growth rates. The year-over-year method is preferred primarily because of the lower volatility of the growth rates. If monthly growth rates are desired, the monthly levels of the Divisia aggregates can be used to compute the month-over-month growth rate, since all of our quantity data are seasonally adjusted.

Consolidation is an accounting convention relevant when numbers are added up. For example, consolidation is necessary to net out the overlap between money-market funds, which include

\footnotetext{
${ }^{16}$ The X-12 ARIMA process is also used by the Federal Reserve Board as in Pierce (1983), the Bank of England as outlined in Thorp (2003), and the European Central Bank (2000) in Seasonal Adjustment of the Monetary Aggregates.

${ }^{17} \mathrm{http}: / /$ www.census.gov/srd/www/x12a/.

${ }^{18}$ There are two possible methods of computing year-over-year Divisia growth rates: (1) the Divisia weights could be based upon the average of the components' expenditure shares between the contemporaneous observation and the one-year lagged observation, or (2) the Divisia index could be chained monthly to produce the level index series, and then the year-over-year growth rates could be computed from the levels series, as advocated by Diewert (1999). We use the latter procedure, since that procedure more closely approaches the continuous-time share weighting and hence produces a higher quality index. We use the year-over-year convention only to produce growth rates. We do not use that approach to produce the levels series.
} 


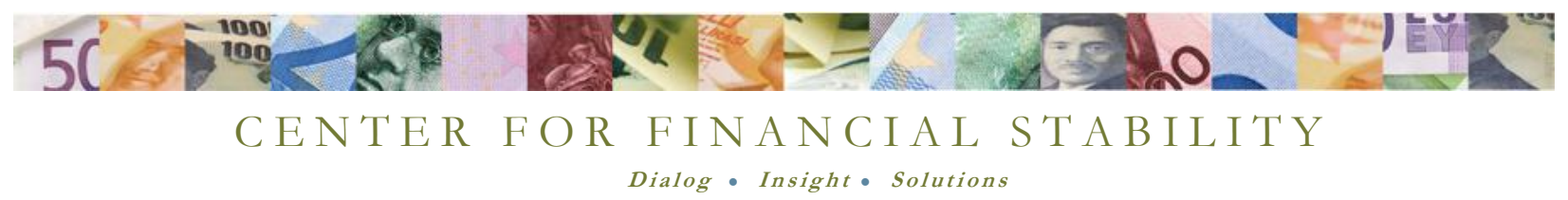

negotiable CDs in their portfolios, and the total market quantities of negotiable CDs. Without consolidation, adding up money-market funds and negotiable CD primary securities would produce double counting. But consolidation is irrelevant to Divisia monetary aggregation, which is based on economic theory and requires market data, not consolidated accounting data. Since we provide no simple-sum monetary aggregates at any level of aggregation, the lack of consolidated data is not a problem for the CFS monetary aggregates.

\section{Entry and Exit of Assets to and from the Aggregates}

Our database extends back in time to 1967. Between 1967 and now, there have been entries and exits of assets from the database. For example, super-Now and MMDA accounts have not been in existence throughout the entire time span. In index number theory, a literature exists on how to deal with such innovations. Crossing the boundary between existence and nonexistence of an asset can severely damage an index number, if done incorrectly. For example, if the Divisia index is used to cross that innovation boundary, the index will explode to plus or minus infinity. The Divisia index uses log changes for growth rates. The quantity growth rate of an asset from a period when an asset does not exist to the next period, when the asset does exist, is infinity. Conversely the quantity growth rate of an asset from a period when an asset does exist to a period when the asset no longer exists is minus infinity.

To deal with this problem, the formal procedure often advocated in the literature is to impute a reservation price to the asset for the period when the asset does not exist and switch to the Fisher ideal index to cross the innovation boundary. We use a different procedure. We do not include an asset in the aggregate during such a transition period. When a new asset appears, we do not enter it into the aggregate until the asset has been in existence for two successive periods. We then use the growth rate from the innovation period to the next period to introduce the asset into the aggregate. Analogously, when an asset disappears from existence, our last entry for that asset is for the growth rate from the prior period to the last period of existence. We never cross the boundary to use the growth rate between a zero entry and a positive entry in either direction.

Our procedure produces no discontinuities. The Divisia index formula is used to produce the growth rate of the aggregate. The growth rates are recursively cumulated to derive the level series, starting from 100. The growth rate during a transition period is computed from the Divisa growth rate of those components not subject to transition during that period. In contrast, simple-sum aggregation introduces a discrete jump into or out of the total, when an asset enters or leaves. Such transitions often result from movement of funds from one discontinued category into another, or from a change in availability of relevant component data. As a result, the resulting simple-sum discontinuous jumps often are severely misleading. Within monetary aggregates, such transitions rarely reflect a technological innovation creating a "new good," and rarely imply invention of a new source of legal means of payment, appropriately weighted the same as cash, as in the simple-sum aggregates. Our procedure produces smooth transitions, with the transition asset's growth not permitted to influence the aggregate's growth rate during the transition period. 


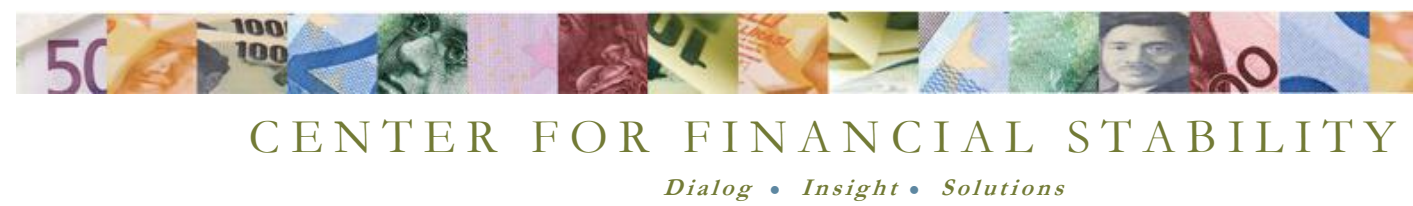

\section{User Cost and Interest Rate Aggregation}

The literature relevant to interest rate aggregation is different from the literature relevant to user-cost aggregation. User-cost aggregation is a form of price aggregation, which is a subject of economic aggregation and index-number theory. User cost measures foregone interest and thereby the opportunity-cost price of consuming the non-investment services of an asset, such as liquidity and means of payment. In contrast, interest rate aggregates, rather than measuring interest foregone, measure interest received as return on investment. Interest rate aggregation is based on elementary accounting principles, not on economic theory.

We use Fisher's factor reversal test formula to compute user-cost price aggregates. By that method, the user cost aggregate over a collection of assets is equal to the user-cost evaluated expenditure on the component assets divided by the aggregation-theoretic aggregate over the component quantities. More formally, suppose the user-cost prices of the $n$ monetary assets, $\mathbf{m}$, are, $\pi$, so the expenditure on the services of the assets is $\sum_{i=1}^{n} \pi_{i} m_{i}$, and suppose $\mathrm{M}(\mathrm{m})$ is the aggregationtheoretic quantity aggregate over $\mathbf{m}$. Then the user cost aggregate is $\Pi(\boldsymbol{\pi})=\sum_{i=1}^{n} \pi_{i} m_{i} / M(\mathbf{m})$, so that $\Pi(\boldsymbol{\pi}) M(\mathbf{m})=\sum_{i=1}^{n} \pi_{i} m_{i}$. We use the discrete time Divisia index to compute the quantity aggregates, as originally derived by Barnett (1980). The user-cost aggregate produced from factor reversal is the dual to the quantity aggregate. Since the Divisia index formula is not self-dual, the user-cost aggregate is not itself a Divisia index. The derivation of the formula for the user cost prices, $\pi$, can be found in Barnett (1980).

The procedure for computing interest rate aggregates, being based on accounting principles, is considerably more elementary than the procedure for computing user cost aggregates. The interest rate aggregate for a portfolio of monetary assets is the single interest rate at which the portfolio would yield the same investment return as the actual return on the portfolio having separate rates of return on each component asset. More formally, suppose a portfolio of $n$ monetary assets, $\mathbf{m}$, is receiving interest rates, $\mathbf{r}$, so the return on the investment is $\sum_{i=1}^{n} r_{i} m_{i}$. Then $\mathbf{r}(\mathbf{r})$ is the aggregate interest rate yield on the portfolio, if $\sum_{i=1}^{n} r(\mathbf{r}) m_{i}=\sum_{i=1}^{n} r_{i} m_{i}$ for any interest rates $\mathbf{r}$. Solving for $r(\mathbf{r})$, we immediately find that $r(\mathbf{r})=\sum_{i=1}^{n} r_{i} m_{i} / \sum_{i=1}^{n} m_{i}$, which is the quantity weighted average of the component interest rates. We use that accounting formula to compute the interest rate aggregates corresponding to each monetary aggregate.

\section{Conclusion}

The purpose of this paper is to document the sources and procedures used in producing the new CFS Divisia monetary aggregates database. Other papers by other authors are already using that data in policy-relevant research, such as Serletis and Gogas (2012) and Belongia and Ireland (2012). But the policy relevance is immediately evident from inspection of Figures $2 a, 2 b, 3 a$, and $3 b$ below. In particular the explanatory power relative to the recent financial crisis and subsequent Great Recession is 


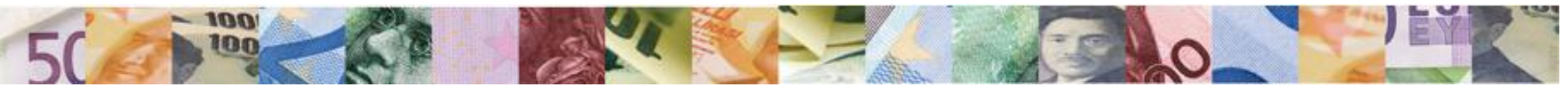

CENTER FOR FINANCIAL STABILITY

Dialog • Insight • Solutions

clear, as is the contrary evidence about the widely expected future inflation, as has been observed by Hanke (2011a,b). In addition, the need for these data are heavily documented and motivated in Barnett (2012). For these reasons, we feel that full disclosure of the data sources and methodology are important. 
CENTER FOR FINANCIAL STABILITY

Dialog - Insight Solutions

\section{Tables and Figures}

Table 1: Components of Aggregates.

\begin{tabular}{|c|c|c|c|c|c|c|c|c|}
\hline Asset & Divisia M1 & Divisia M2M & Divisia MZM & Divisia M2 & Divisia M2 ALL & Divisia M3 & Divisia M4- & Divisia M4 \\
\hline Currency & $\nabla$ & $\nabla$ & $\square$ & $\square$ & $\nabla$ & $\square$ & $\nabla$ & $\nabla$ \\
\hline Travelers Checks & $\square$ & $\nabla$ & $\square$ & $\square$ & $\square$ & $\square$ & $\square$ & $\square$ \\
\hline OCD Commercial & $\square$ & $\square$ & $\nabla$ & $\square$ & $\square$ & $\nabla$ & $\square$ & $\square$ \\
\hline OCD Thrift & $\square$ & $\nabla$ & $\nabla$ & $\square$ & $\square$ & $\nabla$ & $\square$ & $\square$ \\
\hline Retail Money Market Funds & & $\nabla$ & $\nabla$ & $\square$ & $\square$ & $\nabla$ & $\nabla$ & $\square$ \\
\hline Small Time Deposits Commercial & & & & $\nabla$ & $\nabla$ & $\nabla$ & $\nabla$ & $\square$ \\
\hline Small Time Deposits Thrift & & & & $\square$ & $\square$ & $\square$ & $\square$ & $\square$ \\
\hline Institutional Money Market Funds & & & $\nabla$ & & $\square$ & $\nabla$ & $\square$ & $\nabla$ \\
\hline
\end{tabular}


CENTER FOR FINANCIAL STABILITY

Dialog • Insight • Solutions

Figure 1: Nesting of Aggregate Components.

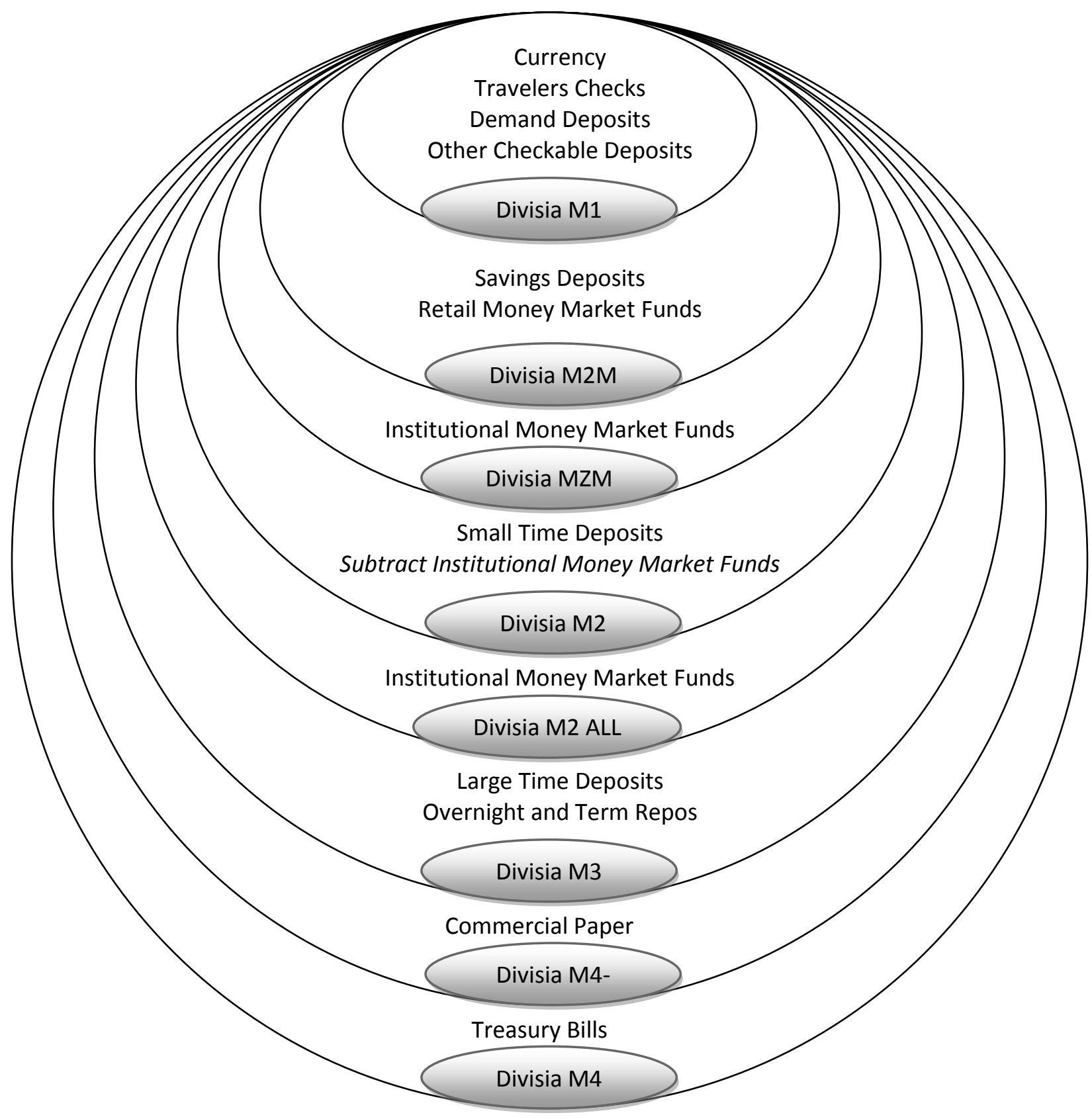


CENTER FOR FINANCIAL STABILITY

Dialog • Insight $•$ Solutions

Table 2: Current Data Sources.

\begin{tabular}{|c|c|c|c|}
\hline Asset & Rate & Rate Source & Level Source \\
\hline Currency & $0 \%$ & NA & FRED / H.6 \\
\hline Travelers Checks & $0 \%$ & NA & FRED / H.6 \\
\hline Demand Deposits & $0 \%$ & NA & FRED / H.6 \\
\hline OCD Commercial & Interest Checking Commercial & Bank Rate Monitor & FRED / H.6 \\
\hline OCD Thrift & Interest Checking Thrift & Bank Rate Monitor & FRED / H.6 \\
\hline Savings Deposits Commercial & MMA Rate Commercial & Bank Rate Monitor & FRED / H.6 \\
\hline Savings Deposits Thrift & MMA Rate Thrift & Bank Rate Monitor & FRED / H.6 \\
\hline Small Time Deposits Commercial & 6-Month CD Rate Commercial & Bank Rate Monitor & FRED / H.6 \\
\hline Small Time Deposits Thrift & 6-Month CD Rate Thrift & Bank Rate Monitor & FRED / H.6 \\
\hline Retail Money Funds & Retail Money Market Funds Rate & iMoneyNet $^{19}$ & FRED / H.6 \\
\hline Institutional Money Funds & Institutional Money Market Funds Rate & iMoneyNet $^{20}$ & FRED / H.6 \\
\hline Commercial Paper & 3-Month AA Financial Commercial Paper Rate & FRED / H.15 & FRED / Commercial Paper Survey \\
\hline Large Time Deposits & 6-Month Secondary CD Rate & FRED / H.15 & FRED / H.8 \\
\hline Overnight and Term Repurchases & I-Repo Index Rate & ICAP (Bloomberg) & Primary Dealer Statistics, NY Fed. \\
\hline Treasury Bills & 3-Month T-Bill Secondary Market Rate & FRED / H.15 & Monthly Survey of Public Debt. \\
\hline Eurodollar Deposits & Eurodollar Deposit Rate & FRED / H.15 & NA \\
\hline Negotiable CD Rate & 3-Month Secondary CD Rate & FRED / H.15 & NA \\
\hline Commercial and Industrial Loans & $\begin{array}{l}\text { Weighted Average Effective Loan Rate, Low Risk, } \\
31 \text { to } 365 \text { Days, All Commercial Banks (EEMLNQ). }\end{array}$ & FRED / E.2 & NA \\
\hline
\end{tabular}

\footnotetext{
${ }^{19}$ Unpublished source of data used by the Federal Reserve. As a substitute starting in November 2011, we use the "iMoneyNet 7-Day Average Yield" found in the Graph Rate Trend Tool on bankrate.com (http://www.bankrate.com/funnel/graph/).

${ }^{20}$ Unpublished source of data used by the Federal Reserve. As a substitute starting in November 2011, we use the "iMoneyNet 7-Day Average Yield" found in the Graph Rate Trend Tool on bankrate.com (http://www.bankrate.com/funnel/graph/).
} 
CENTER FOR FINANCIAL STABILITY

Dialog • Insight • Solutions

Figure $2 a^{21}$ : Growth Rates of Broad Divisia Aggregates January 2004 to January 2012.

\section{Divisia Growth}

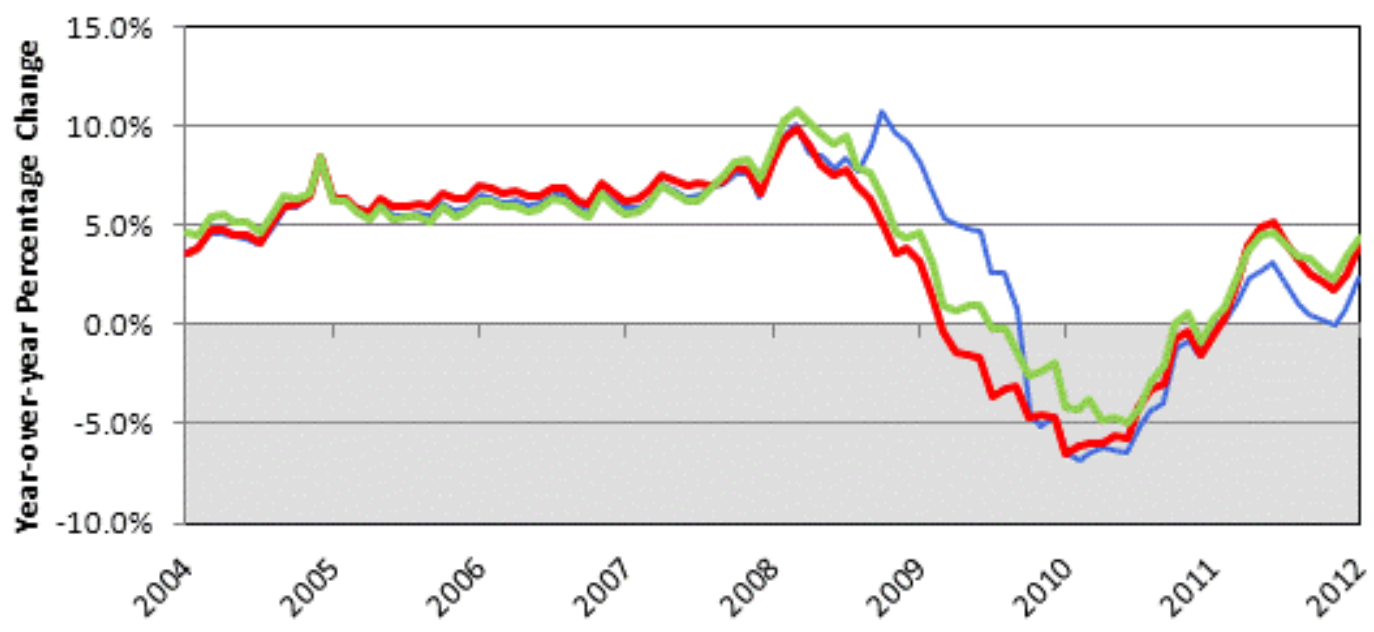

—Divisia M4 Divisia M4- —Divisia M3

Figure 2b: Growth Rates of Broad Divisia Aggregates January 1984 to January 2012.

\section{Divisia Growth}

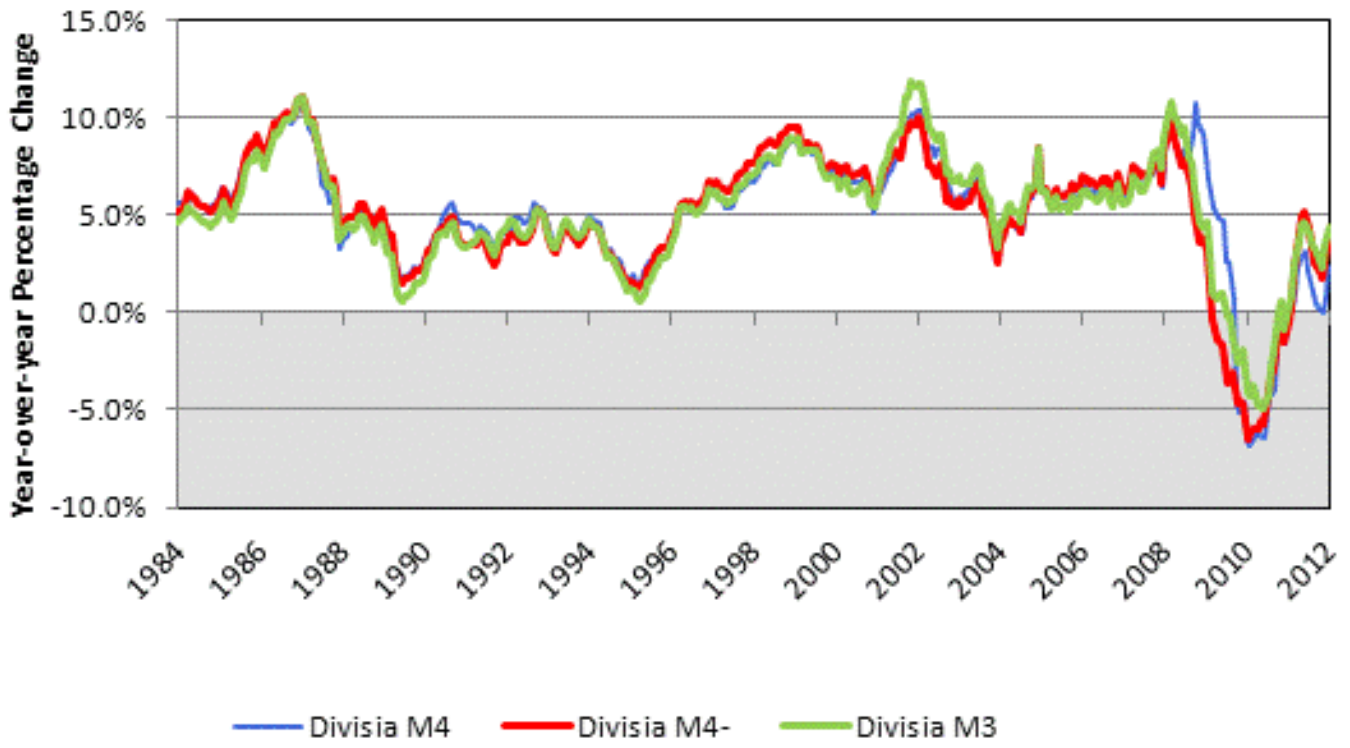

${ }^{21}$ Figures 2a, 2b, 3a, and 3b are taken from the Center for Financial Stability's website, Advances in Monetary and Financial Measurement: http://www.centerforfinancialstability.org/amfm.php 
Figure 3a: Implied Interest Rate of the Divisia Aggregate January 2004 to January 2012.

\section{Interest-Rate Aggregate}

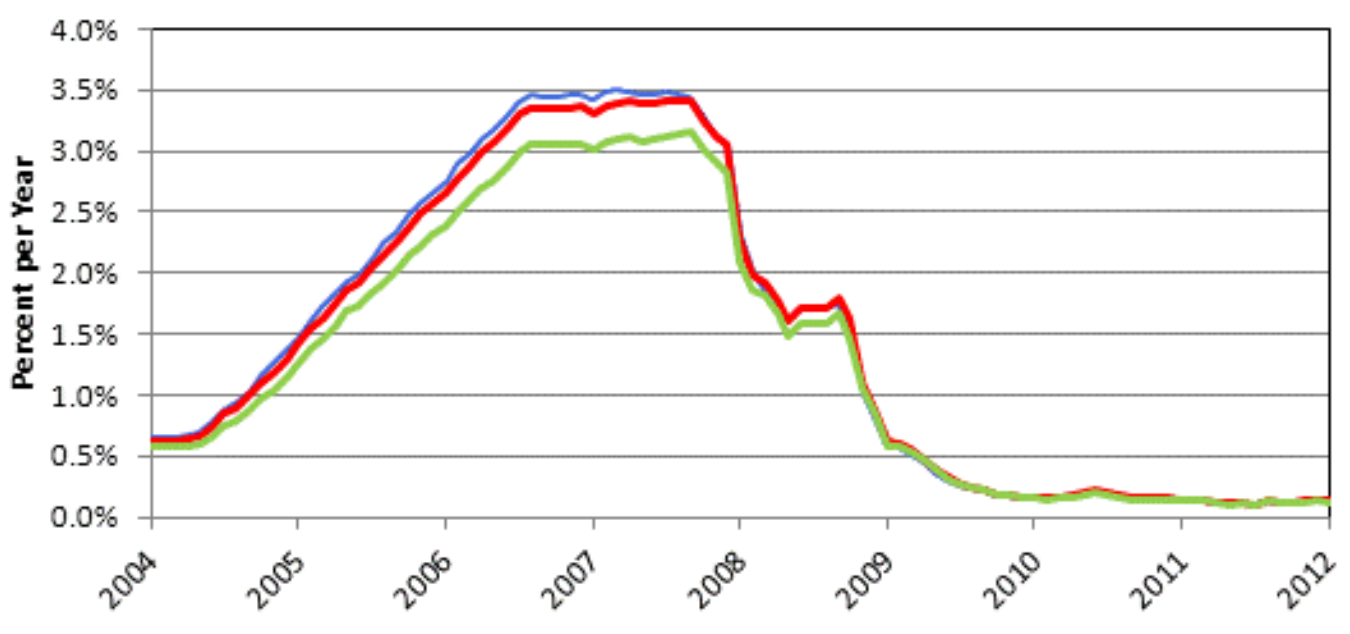

- Divisia M4 Divisia M4- Divisia M3

Figure 3b: Implied Interest Rate of the Divisia Aggregate January 1984 to January 2012.

\section{Interest-Rate Aggregate}

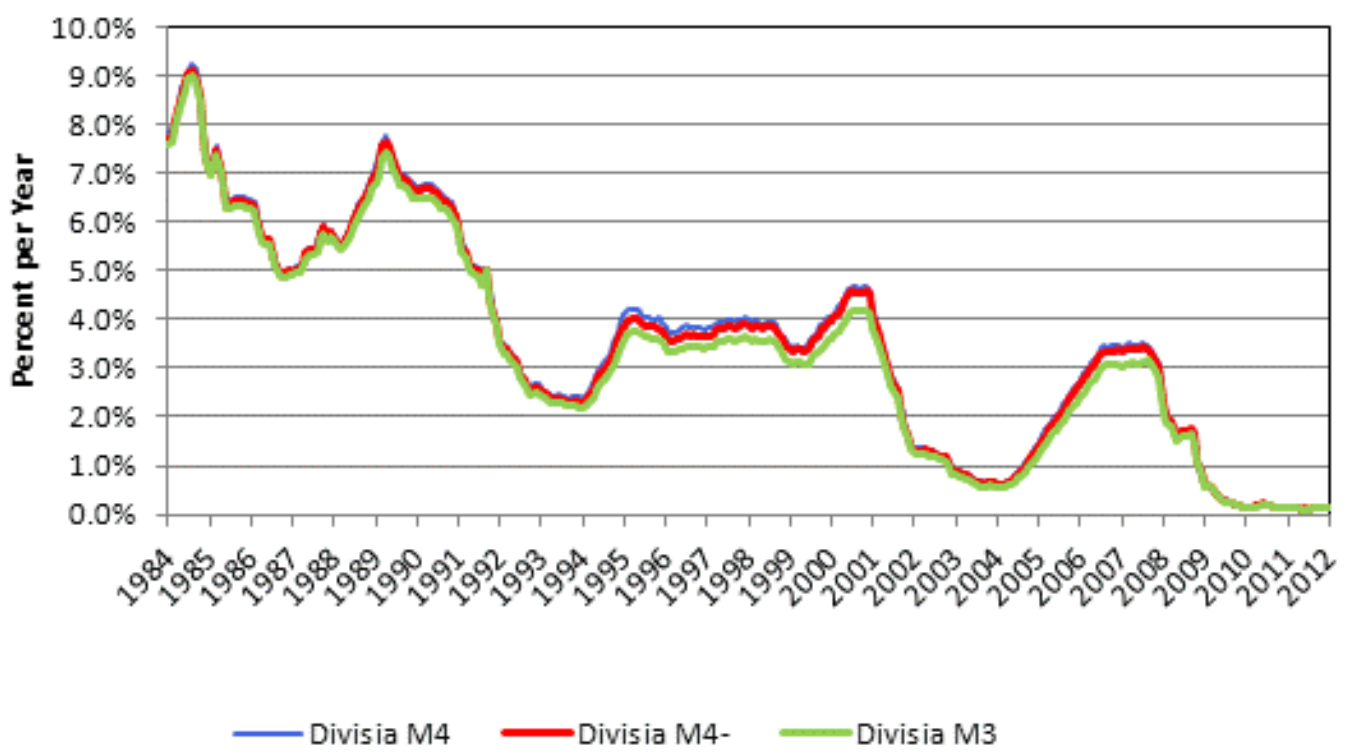




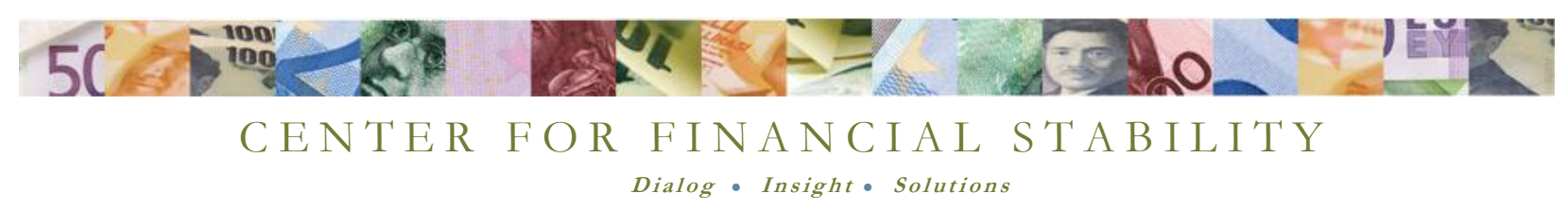

Appendix: Regression Estimates for Broad-Aggregate Component Levels and Rates.

For the broad-aggregate components not all data were available from a single source survey, or in some cases were not available at all for historical values. These levels and interest rates are estimated to fit with the current resources. In all cases a simple linear regression without a constant was used to approximate the past values. These estimations are used in the case of component levels for large denomination time deposits, levels of commercial paper, and levels and rates of repurchase agreements.

Because of the lack of data or the use of two distinct surveys for repo asset levels and interest rates, the past values of the components are estimated using a growth rate method of back calculation. A simple linear regression estimate was taken as well, but the splice produced large jumps at the point in time the series were linked ${ }^{22}$. To avoid this jump, the growth rate method is used for the levels of repos instead. For the linear regression estimate, the values of the estimated survey are about 2.97 times those of the original, while the values for the growth rate method are 2.51 times the original levels. $N Y R E P O_{t}$ is the level of repos from the New York Fed's Primary Dealer Statistics survey, and $R P N S_{t}$ is the monthly overnight and term RPs for commercial banks, available but discontinued on FRED. As previously mentioned, these two surveys are different, since $N Y R E P O_{t}$ takes values for all primary dealers (banks, securities), while $R P N S_{t}$ is described in FRED as only surveying commercial bank deals. The monthly growth rates for each series were calculated, $D N Y R E P O_{t}$ and $D R P N S_{t}$, where $\mathrm{D}$ is the percentage growth rate operator. The growth rates from the FRED series are preserved for the months before October 2001, and then used to back calculate the levels from the initial level of the Primary Dealer Survey. For T, the time of the splice (October 2001), the initial Primary Dealer Survey is used to estimate the last value for repo levels available on FRED:

$$
N Y \widehat{R E P O}_{T-1}={ }^{N Y R E P O}{ }_{T} /\left(1+\operatorname{DRPNS}_{T-1}\right) .
$$

For all the preceding time periods, $0 \leq s \leq T-2$, the levels were estimated following the back calculation pattern and the available levels from the FRED survey:

$$
N Y \widehat{R E P O}_{s}=R P N S_{S+1} /\left(1+D R P N S_{s}\right)
$$

The values for interest rates of repos were not available before 1995, and there was no comparable survey of repo rates from which to estimate. The available repo rates after 1995 were compared graphically to other interest rates, and the T-Bill rate was found to be the closest approximation and most useful, since it is available back to 1967 without any significant splices or changes of survey. Another linear regression without a constant was taken to determine the coefficient for the past values of the I-Repo interest rate index:

\footnotetext{
22 The linear regression without a constant estimate follows the procedures outlined later in this paper for the estimation of the interest rate levels of repurchase agreements, the levels of commercial paper, and large time deposits. The coefficient of estimation was estimated at 2.9723, using the overlapping survey period of October 2001 to March of 2006, and the survey switch occurred in October 2001.
} 


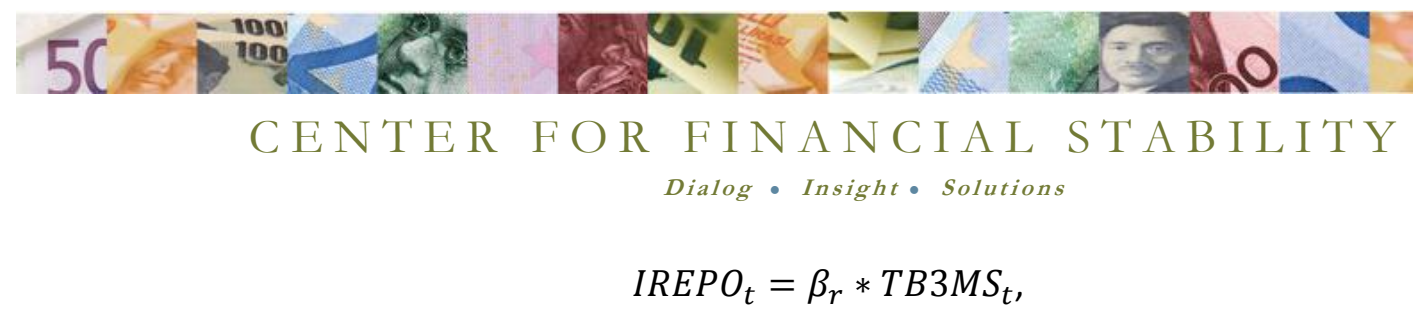

where IREPO ${ }_{t}$ is the IREPO Index, $\beta_{r}$ is the coefficient of the interest rate, and TB3MS $S_{t}$ is the 3-month Treasury bill secondary market (monthly) rate from FRED. For the overlapping period from November 1996 to December 2011, $\beta_{r}$ was estimated, and the past values of the repo interest rate were then determined by:

$$
I \widehat{R E P} O_{t}=\widehat{\beta_{r}} * T B 3 M S_{t}
$$

In addition to estimating repo levels and rates, we spliced the levels for large denomination time deposits and commercial paper to compensate for their collection by two different surveys. The splice again uses a simple linear regression, and estimates the coefficient of the levels between the two surveys without intercept. For commercial paper, both asset level surveys are available from the Federal Reserve Board Statistics website under "Commercial Paper". ${ }^{23}$ The first survey is the "old structure" survey and runs to March of 2006. The "new structure" survey begins in January 2001. For the simple regression, $N S C P_{t}$ is the new structure commercial paper values, while $O S C P_{t}$ are the old structure commercial paper values. For the overlapping time period, $\beta_{C P}$ is estimated by $\widehat{\beta_{C P}}$ and used to model the new survey values before January of 1991, as follows:

$$
\begin{aligned}
& N S C P_{t}=\beta_{C P} * O S C P_{t} \\
& \widehat{N S C P}_{t}=\widehat{\beta_{C P}} * O S C P_{t}
\end{aligned}
$$

Large denomination time deposits face a similar two-survey problem, requiring a splice. Again the same simple linear regression method is used to join the two surveys together. The current values come from the H.8 Survey, available from the Federal Reserve Board Statistics website. The previous values are provided by the FRED series, which were discontinued in March of 2006 along with other M3 components. Since the two series are different in their overlapping time periods, an estimation was needed for those values before 1973. In 1973, the H.8 survey values are used outright, so the only estimation is for those values from 1967 to the end of 1972. The following equations relate $L D T S L_{t}$, which is FRED's seasonally-adjusted monthly level of large time deposits from commercial banks, $H 8 L D T_{t}$, which is the value of large time deposits provided by the H.8 Survey, and $\widehat{\beta_{L T D}}$, which is the estimated value of the coefficient, $\beta_{L T D}$ :

$$
\begin{aligned}
& H 8 L D T_{t}=\beta_{L T D} * L_{D T S} L_{t} \\
& H \widehat{8 L D T} T_{t}=\widehat{\beta_{L T D}} * L D T S L_{t}
\end{aligned}
$$

Table 3 is provided as a quick guide to these estimations. The table provides the sources, the overlapping time period used in the regressions, the time periods within which estimations were used, and the estimated values of the coefficients used to derive the past values.

\footnotetext{
${ }^{23}$ A full description of the differences between the "old" and "new" structure surveys can be found at this website: http://www.federalreserve.gov/releases/cp/about.htm.
} 


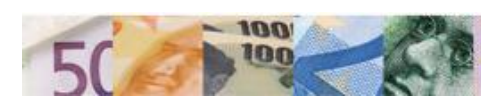

CENTER FOR FIN A N CIAL STABILITY

Table 3: Regression Estimates for Broad Aggregate Components and Rates.

\begin{tabular}{|c|c|c|c|c|c|}
\hline Asset/Rate & Current Source & Previous Source & Overlapping Period & Estimation Period & Coefficient \\
\hline Repo Levels & $\begin{array}{l}\text { NY Fed Primary } \\
\text { Dealer Survey }\end{array}$ & $\begin{array}{l}\text { FRED (Overnight and } \\
\text { Term RPs) }\end{array}$ & $10 / 2001$ to $03 / 2006$ & $01 / 1970$ to $10 / 2001$ & $2.51^{24}$ \\
\hline Repo Rates & I-Repo Index & FRED 3-Month T-Bill Rate & $11 / 1996$ to $12 / 2011$ & $01 / 1970$ to $10 / 1995$ & 1.0768 \\
\hline Commercial Paper Levels ${ }^{25}$ & $\begin{array}{l}\text { Fed Board } \\
\text { Commercial Paper } \\
\text { Survey, New } \\
\text { Structure }\end{array}$ & $\begin{array}{l}\text { Fed Board Commercial } \\
\text { Paper Survey, Old } \\
\text { Structure }\end{array}$ & $01 / 2001$ to $03 / 2006$ & $01 / 1991$ to $01 / 2001$ & 0.9967 \\
\hline Large Time Deposit Levels & H.8 Survey & FRED & $01 / 1973$ to $02 / 2006$ & $01 / 1967$ to $09 / 1973$ & 1.0528 \\
\hline
\end{tabular}

${ }^{24}$ That value is 2.972 , if linear regression without an intercept is used.

${ }^{25}$ Commercial paper levels before January 1991 were taken on a quarterly basis from the Z.1 Flow of Funds Survey, Table L.208. 


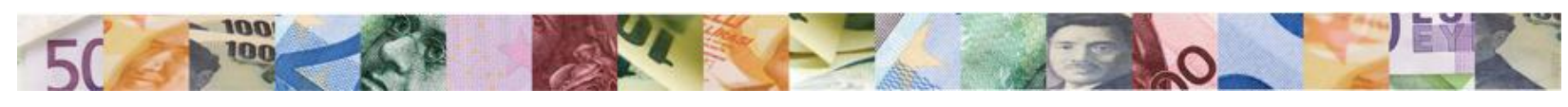

\section{CENTER FOR FINANCIAL STABILITY \\ Dialog • Insight• Solutions}

\section{References}

Anderson, R. G., \& Jones, B. E. (2011). A Comprehensive Revision of the US Monetary Services (Divisia) Indexes. Federal Reserve Bank of St. Louis Review, 93(5), 235-59.

Anderson, R. G., \& Rasche, R. H. (2001). Retail Sweeps Prorams and Bank Reserves 1994 - 1999. Federeal Reserve Bank of St. Louis Review, 83(1), 51-72.

Anderson, R. G., Jones, B. E., \& T.D., N. (1997). Building New Monetary Services Indexes: Concepts, Data, and Methods. Federal Reserve Bank of St. Louis Review, 79.1, 53-82.

Anderson, R., \& Buol, J. (2005, November/December). Revisions to User Costs for the Federal Reserve Bank of St. Louis Monetary Services. Federal Reserve Bank of St. Louis Review, 87(6), 735-749.

Bankrate.com. (2012). Track Economic Index Trends and Graph Financial Industry Rates. Retrieved from http://www.bankrate.com/funnel/graph/

Barnett, W. (1980). Economic Monetary Aggregates: An Application of Index Number and Aggregation Theory. Journal of Econometrics, 14, 11-48. Reprinted in Barnett and Serletis (2000), Chapter 2, pp. 11-48.

Barnett, W. (1982). The Optimal Level of Monetary Aggregation. Journal of Money, Credit, and Banking, 14, 687-710. Reprinted in Barnett and Serletis (2000), Chapter 7, pp. 125-149.

Barnett, W. (2012). Getting it Wrong: How Faulty Monetary Statistics Undermine the Fed, the Financial System, and the Economy. Cambridge, MA: MIT Press.

Barnett, W., \& Serletis, A. (2000). The Theory of Monetary Aggregation. Amsterdam: North-Holland.

Barnett, W., \& Spindt, P. (1982, May). Divisia Monetary Aggregates: Compilation, Data, and Historical Behavior. Board of Governors of the Federal Reserve System Staff Study, 116.

Belongia, M., \& Ireland, P. (2012). Where Simple Sum and Divisia Monetary Aggregates Part: Illustrations and Evidence for the United States. University of Mississippi, working paper.

Cynamon, B., Dutkowsky, D., \& Jones, B. (2006, Fall). Redefining the Monetary Aggregates: A Clean Sweep. Eastern Economic Journal, 32(4), 661-672.

Diewert, W. (1999). Index Number Approaches to Seasonal Adjustment. Macroeconomic Dynamics, 3, 48-68.

European Central bank. (2000). Seasonal Adjustment of Monetary Aggregates and HICP for the Euro Area. Frankfurt, Germany: European Central Bank.

Federal Reserve Bank of New York. (2012). Primary Dealer Statistics XML Data. Retrieved from http://www.newyorkfed.org/xml/gsds_finance.html 


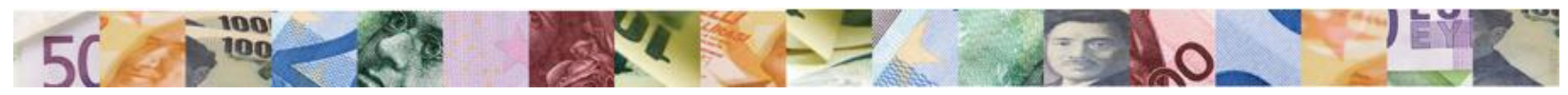

\section{CENTER FOR FINANCIAL STABILITY \\ Dialog • Insight • Solutions}

Federal Reserve Board. (2003, March 23). Federal Reserve Statistical Release: H.6-Monety Stock Measures. Retrieved from Discontinuance of M3.:

www.federalreserve.gov/releases/h6/20060323

Federal Reserve Board of Governors. (n.d.). Statistics and Historical Data. Retrieved 2012, from http://www.federalreserve.gov/releases/h8/current/default.htm

Hanke, S. (2011, October). Malfeasant Central Bankers, Again. Energy Tribune.

Hanke, S. (2011, December). The Whigs Versus the Schoolboys. Globe Asia, 20-22.

Jones, B., Dutkowsky, D., \& Elger, T. (2005). Sweep programs and optimal monetary aggregation. Journal of Banking \& Finances, 29, 483-508.

Serletis, A., \& Gogas, P. (2012). Divisia Monetary Aggregates for Moentary Policy and Business Cycle Analysis. University of Calgary, working paper.

Thornton, D., \& Yue, P. (1992, November/December). An Extended Series of Divisia Monetary Aggregates. Federal Reserve Bank of St. Louis Review, 74(6), 35-52.

Thorp, J. (2003). Change of seasonal adjustment method to X-12 ARIMA. Monetary and Financial Statistics, 4-8.

TreasuryDirect. (2012). Monthly Statement of the Public Debt (MSPD) and Downloadable Files. Retrieved 2012, from http://www.treasurydirect.gov/govt/reports/pd/mspd/mspd.htm

United States Census Bureau. (2012, April). X-12 Arima. Retrieved April 2012, from US Census Bureau: http://www.census.gov/srd/www/x12a/

The Center for Financial Stability (CFS) is a private, nonprofit institution focusing on global finance and markets. Its research is nonpartisan. This publication reflects the judgments and recommendations of the author(s). They do not necessarily represent the views of Members of the Advisory Board or Trustees, whose involvement in no way should be interpreted as an endorsement of the report by either themselves or the organizations with which they are affiliated. 